\title{
A Double Polymerase Chain Reaction Method for Detecting African Swine Fever and Swine Vesicular Disease Virus
}

\author{
Shanzhen Peng ${ }^{1}$, Yin Wang ${ }^{1,2}$, Zexiao Yang ${ }^{1}$, Xueping Yao', Ling $\mathrm{Hu}^{1}$, Ping \\ Chen ${ }^{1}$, Ranyang Ren ${ }^{1}$ and Xingyu Lin ${ }^{1}$ \\ ${ }^{1}$ College of Veterinary Medicine, Sichuan Agricultural University, ${ }^{2}$ Key Laboratory of Animal Disease and Human Health of
} Sichuan Province, Yaan, Sichuan, 625014, China

*For correspondence: Email: yaanwangyin@tom.com; Tel: 86-13208359888

\begin{abstract}
Purpose: To establish a double polymerase chain reaction (PCR) method for the simultaneous detection of African swine fever virus (ASFV) and swine vesicular disease virus (SVDV).

Methods: By using reference sequences of ASFV and SVDV, this study synthesized parts of the genes connected to the 19-T vector which was inserted into competent DH5a cells to establish recombinant plasmids. Two specific primers of ASFV P72 proteins and SVDV genome were designed to amplify the two target genes. Two pairs of primers and two kinds of recombinant plasmids were added to one PCR reaction system to establish a double PCR assay for detection of the two diseases simultaneously. The double PCR conditions were optimized and the sensitivity and specificity of the assay determined.

Results: The reaction was optimal with a final concentration of $0.36 \mu \mathrm{M}$ for each primer, and a final annealing temperature of $55.5^{\circ} \mathrm{C}$. The lowest target gene copy number for detecting SVDV and ASFV was $7.6 \times 10^{2}$ and $1.5 \times 10^{5}$ copies/ $\mu L$, respectively. The assay has a high level of specificity as only the recombinant plasmids of ASFV and SVDV were amplified and control plasmids for three other diseases - porcine circovirus (PCV), pseudorabies virus (PRV), and porcine parvovirus (PPV) - failed amplification.

Conclusion: This study provides a rapid, sensitive and specific double PCR method for the simultaneous detection of ASFV and SVDV.
\end{abstract}

Keywords: African swine fever, Swine vesicular disease, Polymerase chain reaction, Recombinant plasmids

Tropical Journal of Pharmaceutical Research is indexed by Science Citation Index (SciSearch), Scopus, International Pharmaceutical Abstract, Chemical Abstracts, Embase, Index Copernicus, EBSCO, African Index Medicus, JournalSeek, Journal Citation Reports/Science Edition, Directory of Open Access Journals (DOAJ), African Journal Online, Bioline International, Open-J-Gate and Pharmacy Abstracts

\section{INTRODUCTION}

African swine fever (ASF) is an acute, febrile, highly contractive and infectious swine disease caused by African swine fever virus (ASFV) [1-3]. ASFV is a double-stranded DNA virus with an outer membrane coating that has a complex 20 sided symmetry, and a viral genome which is 170 kb-190 kb in overall length and which is currently the only known arbovirus with DNA as its nucleic acid [4]. The clinical manifestations of ASF are quite similar to those of swine fever [5], which include acute fever, accompanied with systemic bleeding and hemorrhage in all the organs. The clinical symptoms range from acute, sub-acute and chronic, manifesting as high fever, skin cyanosis, respiratory disorders and neural symptoms. Once swine is infected with ASF, both the morbidity and mortality can reach $100 \%$ [6]. ASF is listed as one of the major seven swine diseases by OIE and is a Class 1 disease in the list of animal pathogenic microbes in China [7]. 
ASFV can encode more than 34 structural proteins, amongst which the P72 protein can serve as a nucleocapsid protein. The P72 protein is a major structural protein of ASFV, which accounts for $32 \%$ of its virion protein content and has a stable antigenicity $[8,9]$. ASFV is one of the few viruses which cannot react to neutralization reactions and is conserved across different strains [10]. Therefore, it is the most common target antigen for detecting ASFV $[11,12]$.

Swine vesicular disease (SVD) is an acute and febrile infectious disease caused by the swine vesicular disease virus (VDV), which is listed as a Class A infectious disease by OIE [13]. Belonging to small RNA Circoviride Enterovirus, SVDV is a single-stranded positive RNA, virus whose genome is $7400 \mathrm{bp}$ in length $[14,15]$. The genome of SVDV has a large open reading frame which encodes a strain of polyprotein containing 2185 amino acids which produces P1, P2 and P3 by primary pyrolysis. G-C pairs present at low frequency in the base composition, which conforms to that of other enterovirus. The clinical symptoms of this disease feature as blisters or festering of the oral and nasal mucosa and at hoofs causing serious public health problems.

At present, the major laboratory methods for detecting SVD include ELISA detection $[16,17]$, conventional RT-PCR detection and real-time fluorescence RT-PCR detection; each method has associated advantages and disadvantages.

The aim of the paper was to establish a PCRbased assay that can simultaneously detect ASFV and SVDV with high sensitivity and specificity and provide an effective tool for the diagnosis and effective prevention of African swine fever and swine vesicular disease.

\section{EXPERIMENTAL}

\section{Materials}

$2 \times$ Taq PCR MasterMix, DNA Marker DL2000, pMD尺 19-T Vectors were purchased from TaKaRa (Japan). Agarose was obtained from Biowest, and Column DNABACK obtained from the Beijing Tian En Ze Gene Technology Co., Ltd. Competent E. coli DH5a was prepared and preserved by Animal Quarantine Laboratory of Sichuan Agricultural University.

\section{Design and synthesis of primers}

Amplification primers: Primers were carefully designed using DNAMAN according to the sequences data of the ASFV and SVDV published in GenBank (ASFV log-in ID: AY578708 and SVDV log-in ID: EU151461.1). All primers were prepared by TaKaRa. Table 1 shows the sequences of each of the amplification primers.

Synthetic primers of target genes: ASFV (log-in ID: AY578708) and SVDV (log-in ID: EU151461.1) sequences were downloaded from NCBI and primers designed by DNAstar. The length of the ASFV target fragment was $235 \mathrm{bp}$, and the length of SVDV target fragment was 358 bp. Table 2 shows the sequences of the synthetic primers of ASFV, and Table 3 shows the sequences of the synthetic primers of SVDV.

\section{Synthesis of target segment}

The conserved segment sequence fragments of ASFV and SVDV were synthesized in vitro by an overlap extension PCR method using synthetic primers. The primary extension reaction system included $5 \mu \mathrm{L}$ of $10 \times \mathrm{Pfu}$ DNA polymerase buffer, $1 \mu \mathrm{L}$ of Pfu DNA polymerase, $4 \mu \mathrm{L}$ of dNTP (10 $\mathrm{mM}), 1 \mu \mathrm{L}$ of bypass primers (F1-4/R1-4) (10 $\mathrm{mM})$, and $38 \mu \mathrm{L}$ of double distilled water.

Table 1: The sequences of amplification primers

\begin{tabular}{llc}
\hline Pathogen & Primer sequence & Product size (bp) \\
\hline \multirow{2}{*}{ ASFV } & AP1:5'-AACAGCAGGTAAACAAGA-3' & 235 \\
& AP2:5'- ATCCTTTTGCGATGC-3' & \\
SVDV & SP1:5'- CCTCAATTCTCCGTCAGC -3' & 358 \\
\hline
\end{tabular}

Table 2: Synthetic primers of ASFV target genes

\begin{tabular}{cl}
\hline AF1 & AACAGCAGGTAAACAAGATATTACTCCTATTACGGACGCAACGTATCTGGACATAAGAC \\
AF2 & CAAACCCCTAAATACTATCAGCCCCCTCTTGCGCTCTGGATTAAGCTGCGCTTTTGGTT \\
AF3 & CGGTATCCATTCCCTTCGGCGAGCGCTTTATCACCATAAAGCTTGCATCGCAAAAGGAT \\
AR1 & GTATTTAGGGGTTTGAGGTCCATTACAGCTGTAATGAACATTACGTCTTATGTCCAGAT \\
AR2 & GCTGCGCTTTTGGTTTAACGAGAACGTGAACCTTGCTATTCCCTCGGTATCCATTCCCT \\
\hline
\end{tabular}


Table 3: Synthetic primers of SVDV target genes

\begin{tabular}{cl}
\hline SF1 & CCTCAATTCTCCGTCAGCAGAGGAGTGCGGCTATAGTGACAGAGTTAGATCCATCACCT \\
SF2 & TGTGCAAACGTAGTGGTTGGATATGTGTGTGGCCAGCTTACCTGAAAGACGAGGAGGC \\
SF3 & ACGTGGCCACGTGCAGGTTTTACACACTCGAATCTGTGATGTGGCAGCAAGGCTCGCCA \\
SF4 & GTCAAACATGGGGCTATTCGGGCAGAACATGCAGTACCACTACCTCGGGAGAGCCGGGT \\
SR1 & TGCACGTGGCCACGTCGGGTTGGGTGGGTTGATCCTCTGCTGTTGCCTCCTCGTCTTTC \\
SR2 & TGCACGTGGCCACGTCGGGTTGGGTGGGTTGACCTCTGCTGTTGCCTCCTCGTCTTTC \\
SR3 & AGCCCCATGTTTGACAACGCGTCGGGGAACTTCCACCACCAGCCTGGCGAGCCTTGCTG \\
SR4 & GAACTTGGATGCGTTACACTGCACGTGTATTGTGTACCCGGCTCTCCCGA \\
\hline All the primers were diluted to a concentration of $10 \mu M$ according to the manufacturer's instructions and stored \\
at -20 ${ }^{\circ} \mathrm{C}$
\end{tabular}

The secondary extension reaction system included $20 \mu \mathrm{L}$ of two adjacent reaction product from the previous bypass and extension reactions each, $1 \mu \mathrm{L}$ of Pfu DNA polymerase, 1 $\mu \mathrm{L}$ of $10 \times \mathrm{Pfu}$ DNA polymerase buffer, and $8 \mu \mathrm{L}$ of dNTP (10 mM).

Primary and secondary extension reactions were conducted at $94{ }^{\circ} \mathrm{C}$ for $30 \mathrm{~s}$ and $72{ }^{\circ} \mathrm{C}$ for $15 \mathrm{~min}$, respectively.

\section{Amplification and identification of target genes}

The $50 \mu \mathrm{L}$ reaction system contained $25 \mu \mathrm{L}$ of 2 $\times$ Taq PCR MasterMix, $18 \mu \mathrm{L}$ of double distilled water, $1 \mu \mathrm{L}$ of ASFVP1, $1 \mu \mathrm{L}$ of ASFVP2, $1 \mu \mathrm{L}$ of SVDVP1, $1 \mu \mathrm{L}$ of SVDVP2 and $3 \mu \mathrm{L}$ of products from the secondary extension reaction. The amplification reaction was performed at $94{ }^{\circ} \mathrm{C}$ for $4 \mathrm{~min}$ (initial denaturation), $94{ }^{\circ} \mathrm{C}$ for $50 \mathrm{~s}$ (denaturation), $55{ }^{\circ} \mathrm{C}$ for $45 \mathrm{~s}$ (annealing), $72{ }^{\circ} \mathrm{C}$ for $1 \mathrm{~min}$ (extension) for 30 cycles ending at 72 ${ }^{\circ} \mathrm{C}$ for $10 \mathrm{~min}$ (overall extension). PRC products were stored at $-20{ }^{\circ} \mathrm{C}$.

The PCR products were detected using $1 \%$ agarose gel electrophoresis and connecting the products to a $\mathrm{pMD} \otimes$ 19-T Vector after gel extraction and purification. A $10 \mathrm{uL}$ reaction system contained $5 \mu \mathrm{L}$ of solution I, $1 \mu \mathrm{L}$ of $\mathrm{pMD} \otimes$ 19-T Vector, and $4 \mu \mathrm{L}$ gel extraction products. The reaction system was maintained at $16{ }^{\circ} \mathrm{C}$ overnight and inserted into competent $\mathrm{DH} 5 \alpha$ cells for cloning. The bacterial liquid was aliquoted into different EP tubes at a ratio of $7: 3$ (bacterial liquid: glycerine). Samples were processed for sequencing analysis and others were stored at $-70^{\circ} \mathrm{C}$.

\section{Establishment of double PCR method}

An aliquot of $20 \mu \mathrm{L}$ of the double PCR system contained ASFVP1, ASFVP2, SVDVP1 and SVDVP2 in the same system (the concentration range of the primers is $0.04-0.6 \mu \mathrm{M}), 10 \mu \mathrm{L}$ of 2 $\times$ Taq PCR MasterMix, $2 \mu \mathrm{L}$ of ASFV bacterial liquids, $2 \mu \mathrm{L}$ of SVDV bacterial liquids and double distilled water. In order to optimize the annealing temperature, 50, 51, 52.9, 55.5, 59.1, 62, 63.8 and $65{ }^{\circ} \mathrm{C}$ were selected to test reactions. The reaction procedure was as follow: $95{ }^{\circ} \mathrm{C}$ for $5 \mathrm{~min}, 94{ }^{\circ} \mathrm{C}$ for $30 \mathrm{~s}$, annealing temperatures for $45 \mathrm{~s}, 72{ }^{\circ} \mathrm{C}$ for $30 \mathrm{~s}, 30$ cycles, ending at $72{ }^{\circ} \mathrm{C}$ for $10 \mathrm{~min}$. The PCR products were detected by $1 \%$ agarose gel electrophoresis.

\section{Specificity experiment}

The specificity of double PCR with the two pairs of specific primers was assessed by comparing the recombinant plasmids containing the target ASFV and SVDV fragments to the Porcine circovirus (PCV), Porcine pseudorabies (PRV), and porcine parvovirus (PPV).

\section{Sensitivity experiment}

To assess the sensitivity, the recombinant plasmids constructs were measured using a ND1000 ultraviolet spectrophotometer (Nano Drop Co, Ltd, USA) and amplified in a 10-fold serial dilution by PCR using the optimum reaction system and conditions as described above. Quantitative results showed that the concentration of the ASFV and SVDV gel extraction products were $40 \mathrm{ng} / \mu \mathrm{L}$ and $30 \mathrm{ng} / \mu \mathrm{L}$ respectively. The calculation formula of gene copy number concentration is: $\left(6.02 \times 10^{23}\right) \times$ (sample concentration $\left.\mathrm{ng} / \mu \mathrm{L} \times 10^{-9}\right) /($ DNA length $\times$ 660) $=$ copies $/ \mu \mathrm{L}$.

\section{RESULTS}

\section{Amplification and identification of target genes}

The recombinant plasmids of ASFV and SVDV were used as the templates and amplified by the specific primers of ASFV and SVDV. The reaction products were detected by $1 \%$ agarose gel electrophoresis. The results showed that ASFV and SVDV amplify fragments at the lengths of $235 \mathrm{bp}$ and $358 \mathrm{bp}$ respectively, which 
conformed to the length of expected target gene fragments (Fig. 1).

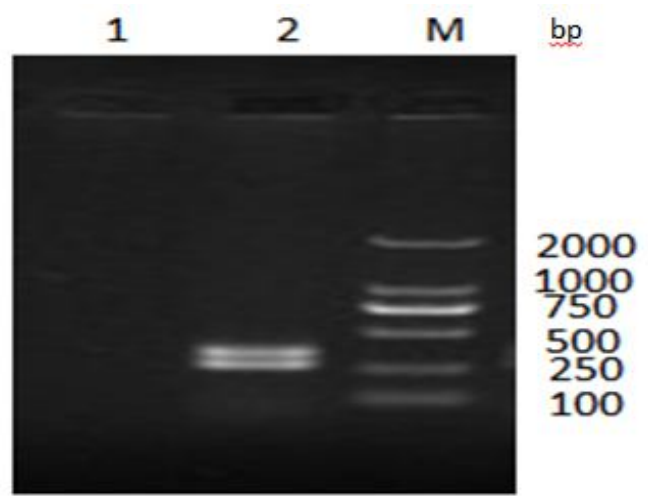

Fig 1: Identification of recombinant plasmids. Note: 1 = negative control; 2 = recombinant plasmids; and 3 = DNA marker DL2000

The previously selected target genes of ASFV and SVDV were compared for homology (in www.NCBI.com) and the results showed $100 \%$ homology, indicating that the target genes are correctly synthesized.

\section{Optimization of double PCR reaction conditions}

\section{Optimization of annealing temperature}

The optimal anneal temperature results are shown in Fig. 2. In consideration of the effect of temperature on annealing and specificity, the optimum annealing temperature was $55.5^{\circ} \mathrm{C}$.

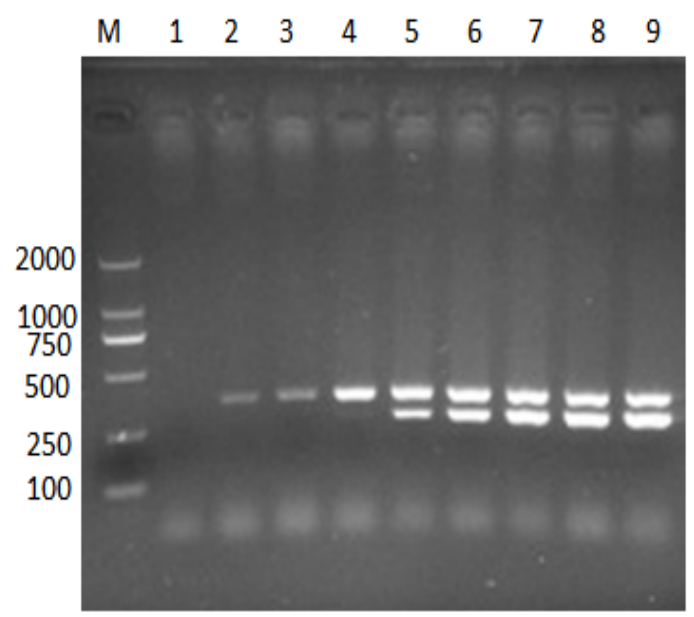

Fig 2: Optimization of annealing temperature. Note: $M$ = DNA marker DL2000; 1 = negative control; 2 - $9=$ annealing temperature of $65,63.8,62,59.1,55.5$, $52.9,51$ and $50{ }^{\circ} \mathrm{C}$, respectively

\section{Optimization results of primer concentration} When the final concentration of each specific primer reached 0.04 0.6 $\mu \mathrm{M}$, the amplification results are as shown in Fig. 3. For reaction efficiency and reduction of primer dimmer formation, the optimal final concentration of primers was shown to be $0.36 \mu \mathrm{M}$.

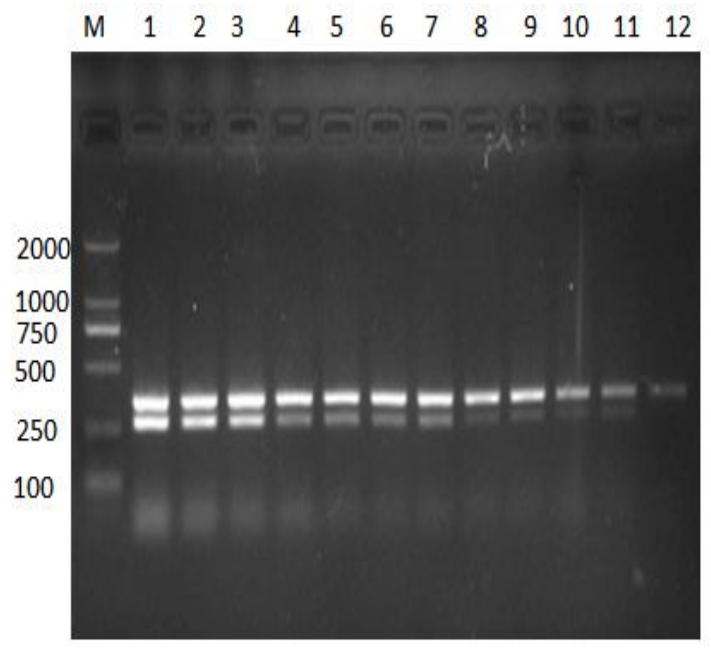

Fig. 3: Optimization of primer concentration. Note: M = DNA marker DL2000; 1 - 12 = respective primer concentration $0.6,0.48,0.36,0.3,0.24,0.2,0.18$, $0.16,0.12,0.08,0.06$ and $0.04 \mu \mathrm{M}$

\section{Specificity results from double PCR}

PCR amplification of ASFV, SVDV, PCV, PRV and PPV using the optimized double PCR conditions are shown in Fig. 4. Lane 4 demonstrates the only amplification specific products at lengths of $235 \mathrm{bp}$ and $358 \mathrm{bp}$. The amplification results of PCV, PRV and PPV pathogens are all negative, indicating that the double PCR method is highly specific.

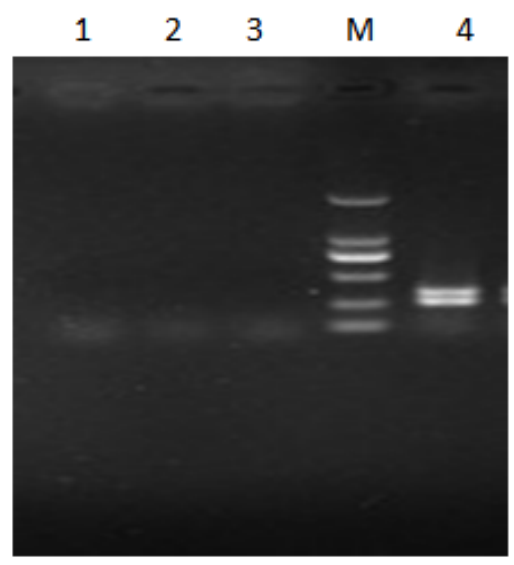

Fig 4: Specificity results. Note: $1-3=\mathrm{PCV}, \mathrm{PRV}$, and PPV, respectively; $\mathrm{M}=$ DNA marker DL2000; 4 = mixed bacterial liquids of ASFV and SVDV 


\section{Sensibility experiment on double PCR}

The results of sensibility experiment are shown in Fig. 5. It is observed from Fig. 5 that SVDV in lane 2 still presents obvious specific amplification with a sensitivity to the target genes of $7.6 \times 10^{2}$ copies/ $\mu \mathrm{L}$. ASFV in lane 4 presents obvious specific amplification with a sensitivity to the target genes of $1.5 \times 10^{5}$ copies $/ \mu \mathrm{L}$.

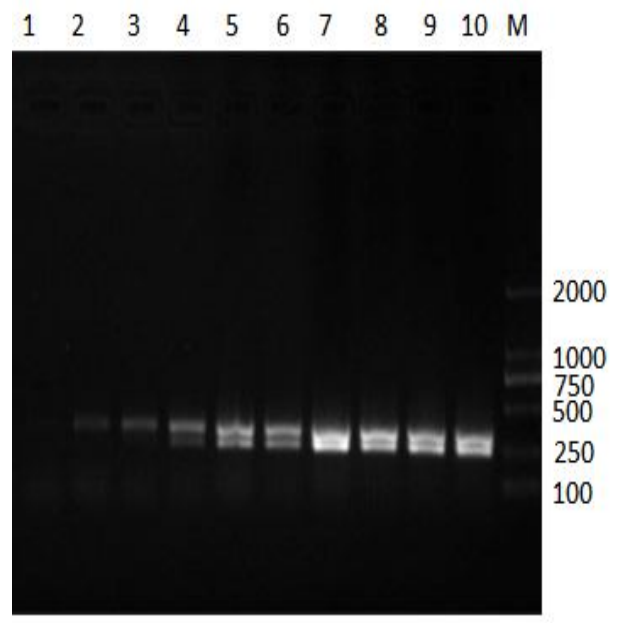

Fig 5: Sensibility results. Note: $1-10=$ ASFV target genes copy numbers, viz, $1.5 \times 10^{2}, 1.5 \times 10^{3}, 1.5 \times 10^{4}$, $1.5 \times 10^{5}, 1.5 \times 10^{6}, 1.5 \times 10^{7}, 1.5 \times 10^{8}, 1.5 \times 10^{9}, 1.5 \times 10^{10^{\prime}}$ and $1.5 \times 10^{11}$ copies $/ \mu \mathrm{L}$, respectively: $1-10=$ SVDV target genes copy numbers, viz, $7.6 \times 10^{1}, 7.6 \times 10^{2}$, $7.6 \times 10^{3}, 7.6 \times 10^{4}, 7.6 \times 10^{5}, 7.6 \times 10^{6}, 7.6 \times 10^{7}, 7.6 \times 10^{8}$, $7.6 \times 10^{9}$ and $7.6 \times 10^{10}$ copies $/ \mu \mathrm{L}$, respectively; $\mathrm{M}=$ DNA marker DL2000

\section{DISCUSSION}

ASF is a serious disease that can cause huge economic losses in the swine industry. The number of swine in China accounts for half of the total number in the world and our consumption of pork is ever increasing, which requires increasing quantity of pork imported from abroad. Therefore, the development of a healthy and robust swine industry is extremely important and has a significantly influences the food safety and national security in China.

Currently, there is no ASFV in China and ASF epidemics in the adjacent areas between Russia and China. However, the constant spreading of ASF epidemics within Russia and the frequent, rapid and long-distance trading of animals and commodities around the globalized world make it increasingly difficult to guarantee that food is free from pathogenic bacteria, virus or epidemics, such as ASFV. Therefore, we must remain on high alert and conduct risk analysis to prevent ASF from entering in China [18]. Besides, SVD's damage to swine industry has been continuously increased in recent years. Therefore, it is significant for ensuring the healthy development of swine industry in China by establishing a rapid and accurate method for simultaneously detecting ASF and SVD.

To our knowledge, many available techniques such as RT-PCR, real-time RT-PCR and ELISA have been developed for ASFV detection in the endemic areas, but there was few studies on ASFV including the ASFV detecting methods in China and some other non-endemic countries because ASF have not happened in the boundary regions and there is no ASF strains used for researches in China.

This study designs two kinds of specific primers for ASFV P72 proteins and SVDV genome respectively and synthesizes target genes. By optimizing the annealing temperature and other reaction conditions for the double PCR assay, this study guarantees the amplification efficiency of the two couples of specific primers in the specific reaction. The double PCR method established in this study can rapidly detect and identify ASFV and SVDV in one reaction system. It shows good specificity and sensitivity, and can be directly used for the detection of clinical epidemic materials in samples, offering an effective tool for the diagnosis, and prevention and control of ASF and SVD. It was the first time to establish an assay to detect the two diseases simultaneously in China. In conclusion, the designed primers and the double PCR described in this paper supplied important materials and a rapid useful technological reserve for ASFV and SVDV detection and set basis for the studies about ASFV detection in China.

\section{CONCLUSION}

The findings indicate that double PCR approach is a rapid, sensitive and specific method for detecting ASFV and SVDV simultaneously.

\section{ACKNOWLEDGEMENT}

This work was supported by Twelfth Five-YearPlan in National Science and Technology for Rural Development in China (no. 2013BAD12B04).

\section{REFERENCES}

1. Wang Z, Ma L. Gold nanoparticle probes. Coord Chem Rev 2009; 253(11): 1607-1618.

2. Wang $H$, Wang JW, Xu TG, Wang ZL. Advances in studies of epidemiology and diagnostic technologies 
for African swine fever. Chin Vet Sci 2008; 38(06): 544-548.

3. Penrith ML. African swine fever: transboundary diseases. Onderstepoort J Vet Res 2009; 76(1): 91-95.

4. Yáñez RJ, Rodríguez JM, Nogal ML, Yuste L, Enríquez $C$, Rodriguez JF, Viñuela E. Analysis of the complete nucleotide sequence of African swine fever virus. Virology 1995; 208(1): 249-278.s

5. Maurer FD, Griesemer RA, Jones TC. African swine fever. Diseases of Swine. 2nd ed. lowa State University Press, Ames 1964; 187-202.

6. Hess WR. African swine fever: a reassessment [Virus strains]. Adv Vet Sci Comp Med; 1981.

7. Lubisi BA, Bastos ADS, Dwarka RM, Vosloo W. Molecular epidemiology of African swine fever in East Africa. Arch. Virol 2005; 150(12): 2439-2452.

8. Garcia-Barreno B, Sanz A, Nogal ML, Vinuela E, Enjuanes L. Monoclonal antibodies of African swine fever virus: antigenic differences among field virus isolates and viruses passaged in cell culture. $J$ Virol 1986; 58(2): 385-392.

9. Lopez-Otin C, Freije J MP, Parra F, Mendez E, Vinuela E. Mapping and sequence of the gene coding for protein $\mathrm{p72}$, the major capsid protein of African swine fever virus. Virology 1990; 175(2): 477-484.

10. Gomez-Puertas P, Rodriguez F, Oviedo JM, RamiroIbanez F, Ruiz-Gonzalvo F, Alonso C, Escribano JM. Neutralizing antibodies to different proteins of African swine fever virus inhibit both virus attachment and internalization. J Virol 1996; 70(8): 5689-5694.

11. Yu M, Morrissy CJ, Westbury HA. Strong sequence conservation of African swine fever virus p72 protein provides the molecular basis for its antigenic stability. Arch Virol 1996; 141(9): 1795-1802.

12. Borca MV, Irusta P, Carrillo C, Afonso, CL., Burrage $T$, Rock DL. African swine fever virus structural protein p72 contains a conformational neutralizing epitope. Virology 1994; 201(2): 413-418.

13. Armstrong RM, Barnett ITR. An enzyme-linked immunosorbent assay (ELISA) for the detection and quantification of antibodies against swine vesicular disease virus (SVDV). J Virol Methods 1989; 25(1): 71-79.

14. Seechurn P, Knowles NJ, McCauley JW. The complete nucleotide sequence of a pathogenic swine vesicular disease virus. Virus Res 1990; 16(3): 255-274.

15. Inoue T, Yamaguchi S, Kanno T, Sugita S, Saeki T. The complete nucleotide sequence of a pathogenic swine vesicular disease virus isolated in Japan (J1'73) and phylogenetic analysis. Nucleic Acids Res 1993; 21(16): 3896.

16. Ferris NP, Dawson M. Routine application of enzymelinked immunosorbent assay in comparison with complement fixation for the diagnosis of foot-andmouth and swine vesicular diseases. Vet Microbiol 1988; 16(3): 201-209.

17. Ferris NP, Powell $H$, Donaldson Al. Use of pre-coated immunoplates and freeze-dried reagents for the diagnosis of foot-and-mouth disease and swine vesicular disease by enzyme-linked immunosorbent assay (ELISA). J Virol Methods 1988; 19(3): 197-206.

18. Rowlands RJ, Michaud V, Heath L, Hutchings G., Oura C, Vosloo W, Dixon LK. African swine fever virus isolate, Georgia, 2007. Emerging Infect Dis 2008; 14(2): 1870-1874. 